\title{
Modeling Large Deformation and Failure of Expanded Polystyrene Crushable Foam Using LS-DYNA
}

\author{
Qasim H. Shah and A. Topa \\ Department of Mechanical Engineering, Faculty of Engineering, International Islamic University Malaysia, 53100 Jalan Gombak, \\ Kuala Lumpur, Malaysia
}

Correspondence should be addressed to Qasim H. Shah; qasim.h.shah@gmail.com

Received 31 May 2013; Accepted 31 October 2013; Published 27 January 2014

Academic Editor: Dimitrios E. Manolakos

Copyright (C) 2014 Q. H. Shah and A. Topa. This is an open access article distributed under the Creative Commons Attribution License, which permits unrestricted use, distribution, and reproduction in any medium, provided the original work is properly cited.

\begin{abstract}
In the initial phase of the research work, quasistatic compression tests were conducted on the expanded polystyrene (EPS) crushable foam for material characterisation at low strain rates $\left(8.3 \times 10^{-3} \sim 8.3 \times 10^{-2} \mathrm{~s}^{-1}\right)$ to obtain the stress strain curves. The resulting stress strain curves are compared well with the ones found in the literature. Numerical analysis of compression tests was carried out to validate them against experimental results. Additionally gravity-driven drop tests were carried out using a long rod projectile with semispherical end that penetrated into the EPS foam block. Long rod projectile drop tests were simulated in LS-DYNA by using suggested parameter enhancements that were able to compute the material damage and failure response precisely. The material parameters adjustment for successful modelling has been reported.
\end{abstract}

\section{Introduction}

Crushable foams are suitable solution in the field of shock mitigation and impact absorption applications because of their incombustibility, cost, complex compression behavior, and high energy absorption capabilities [1]. In safety applications, accurate predictions of behaviour of shock absorber materials are extremely important because the experimental work is a resource hungry process.

Throughout the past years, the range of applications of crushable foams has become wider and larger as engineers and designers keep altering the microstructure of the foam materials in order to achieve the desired mechanical properties and behaviour that fulfil the requirements regarding their applications. Crushable foams are mainly used in cushioning, impact mitigation, energy absorption, and comfort applications [2].

One way to increase the car body stiffness and crashworthiness is the utilization of local reinforcements with synthesized polyurethane foam. The crushable foams have several advantages over other reinforcement materials because of their high energy absorbing capabilities, coupled with their low cost and weight [3].
Another important application of the crushable foams is the aircraft runway arrestor systems. The aircraft might overrun the available runway area during take-off or landing. Crushable foam arrestor bed systems mitigate the overrun which prevents accidents involving aircraft damage and loss of life [4].

In automotive safety, the crushable foams are used in the new Steel And Foam Energy Reducing (SAFER) barriers. In many NASCAR racetracks, simple crushable polystyrene insulation foam blocks are placed between the outer steel tube, and the inner concrete wall. This SAFER barrier is very low in cost and weight and easy to fabricate $[5,6]$.

Another application for the crushable foams is in oil well casing. Heat is generated due to the normal drilling and production applications. As temperature rises, the trapped fluids tend to expand and potentially can create a very high pressure. The most effective mitigation solution for this pressure build-up is the application of crushable foam wrap. This will allow the fluid trapped within the casing annulus to expand. The crushable foam wrap is predetermined to collapse before any potential dangerous pressure may exist [7]. 
Extensive experimental work has been conducted to determine the mechanical properties of expanded polystyrene foams. Difficulties arise in modelling these types of materials because they are stain rate dependant. Previous studies show that the rate dependant behaviour is linear with the logarithm of the strain rate [2]. Moreover, the mechanical properties of polymeric foams depend on their density $[8,9]$. Therefore, developing the material model depends on the density of the foams and their applications.

The complexity of the mechanical behaviour of the crushable foams is a consequence of its cellular structure. Compression is the most common mode of deformation for crushable foams as they are weak in tension and shear. However, tension and shear deformation can occur due to concentrated compressive loads or the geometry of crushable foams [2].

In pure compression, there are three regions in the stressstrain relationship: linear compression, stress plateau, and non-linear compression. Poisson's ratio is negligible in pure compression. In pure tension, the material behaves linearly in low deformation. However, nonlinear behaviour is observed at large deformations $[10,11]$.

In previous work, material models for EPS foams were developed. These models were proved to be successful in the cases of uniform compression loading and low velocity localized damage $[5,6,12,13]$. However, during high velocity localized compression, the material undergoes a combined mode of compression and tension. Brittle rupture and crack initiation are experimentally observed in the material $[14,15]$. Therefore, these material models need to be improved to include the brittle failure behaviour.

\section{Experimental Work}

2.1. QuasiStatic Compression Test. The quasistatic compression tests were conducted on cubic specimens of EPS crushable foam with the side length of $100 \mathrm{~mm}$. The average density of the specimen was measured as $12.75 \mathrm{~kg} / \mathrm{m}^{3}$. The specimen was compressed until $80 \%$ of its initial length. The compression test was carried out at three different compression rates: $50 \mathrm{~mm} / \mathrm{min}, 250 \mathrm{~mm} / \mathrm{min}$, and $500 \mathrm{~mm} / \mathrm{min}$ and the strain rates for these three compression rates were calculated as $0.00833 / \mathrm{s}, 0.04167 / \mathrm{s}$, and $0.0833 / \mathrm{s}$, respectively.

Upon examining the specimen during the compression test, no lateral elongation was observed as seen in Figure 1. This proves that EPS crushable foams have zero Poisson's ratio. The volume of the material is not conserved during compression. Instead, the density increases while the material is compressed. Poisson's ratio plays an important role in stress strain diagrams. The initial and final cross section areas of the EPS crushable foams in compression remain constant. Thus, the engineering and true stress strain diagrams are identical.

When the compressive load was removed, the specimen elastically recovered to approximately $50 \%$ of its initial length. This is due to the elastic component (matrix material) of polymeric foams. However, a permanent damage is observed because of the foam cells collapsing in the stress plateau region.

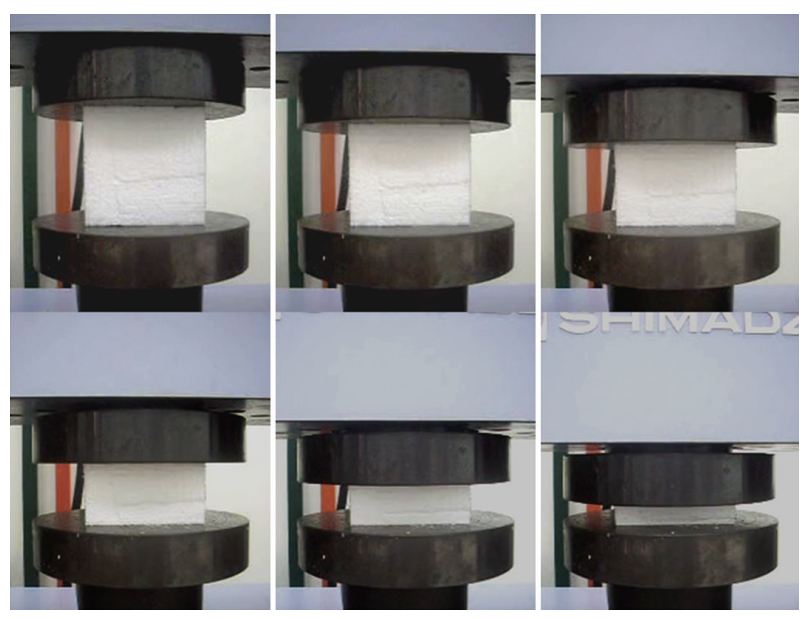

FIGURE 1: Quasistatic compression test of EPS crushable foam.

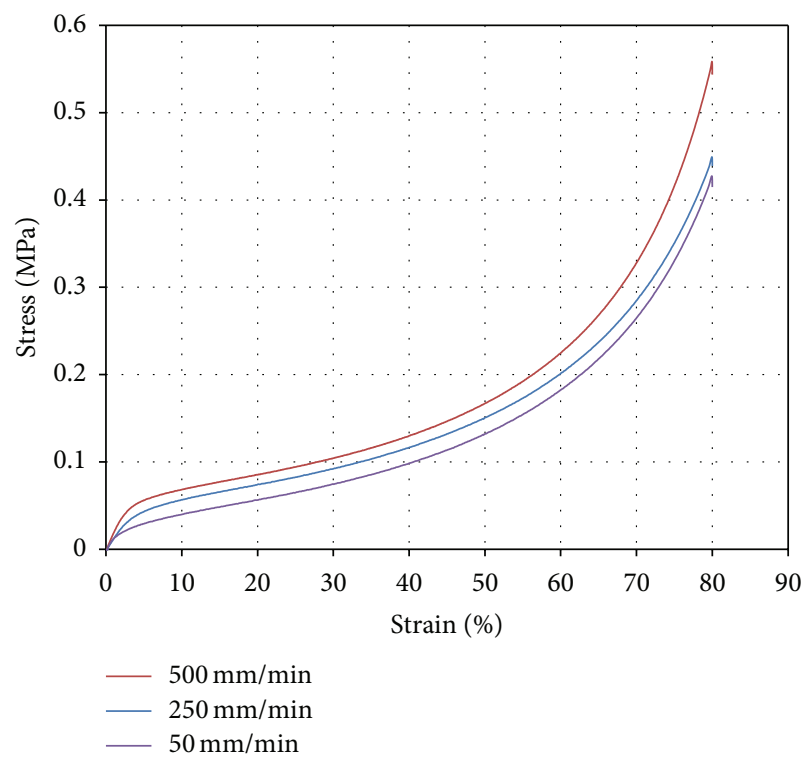

FIGURE 2: Rate dependency of EPS crushable foam.

TABLE 1: Effects of strain rate on yield stress, Young's Modulus, and absorbed energy.

\begin{tabular}{lccc}
\hline $\begin{array}{l}\text { Strain rate } \\
\left(\mathrm{s}^{-1}\right)\end{array}$ & $\begin{array}{c}\text { Yield stress } \\
(\mathrm{MPa})\end{array}$ & $\begin{array}{c}\text { Young's Modulus } \\
(\mathrm{MPa})\end{array}$ & $\begin{array}{c}\text { Absorbed energy } \\
(\mathrm{J})\end{array}$ \\
\hline 0.00833 & 0.020 & 0.8 & 104.89 \\
0.04167 & 0.035 & 1.4 & 118.95 \\
0.08333 & 0.055 & 2.2 & 135.06 \\
\hline
\end{tabular}

The results of the compression test are plotted in Figure 2. The three regions of deformation are observed in EPS crushable foams. However, the transition point between the stress plateau and densification regions are not clear. This is believed to be due to the destruction of foam cells and the permanent damage. The yield stress, Young's Modulus and total absorbed energy by the foam material are listed in Table 1 . 


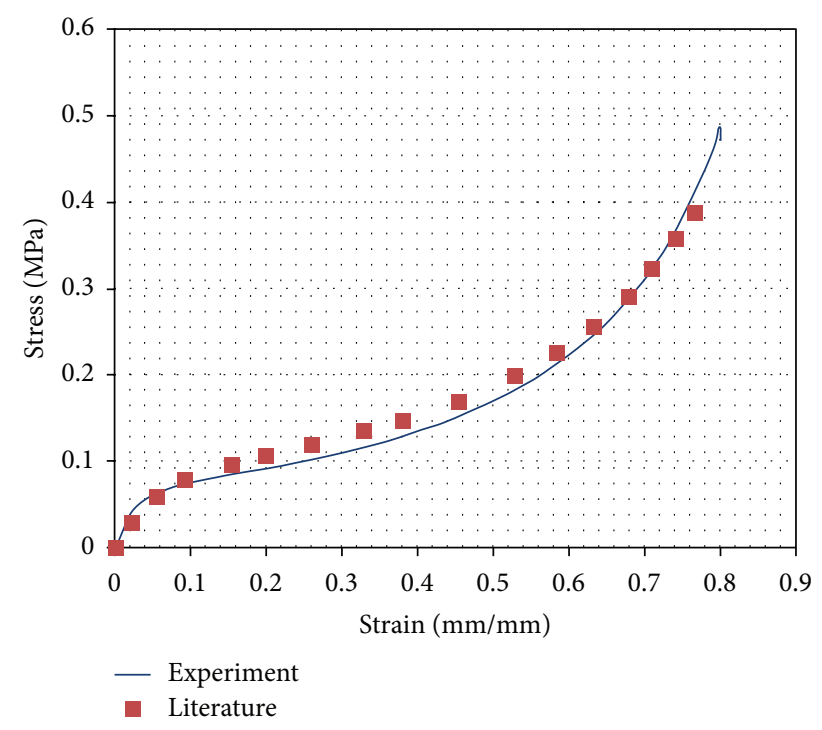

Figure 3: Comparison between literature data and experimental data.
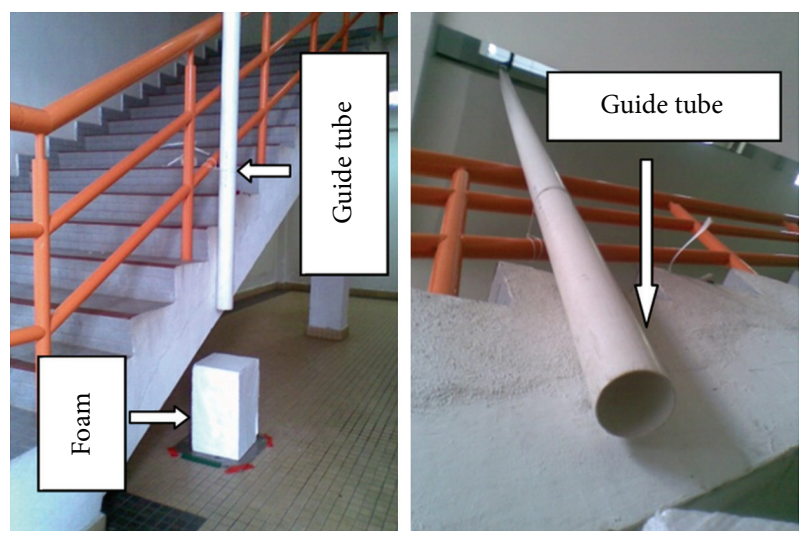

FIGURE 4: Set-up for drop test experiment.

To validate the results of the experiment, the stress strain curve at a strain rate of $0.0833 \mathrm{~s}^{-1}$ was compared to the stress strain curves found in the literature [2]. As observed in Figure 3, there is a slight difference in the two curves. This is because of the small difference in the strain rate and the density of the material. The specimen in the literature had slightly higher density and the strain rate was a little larger.

2.2. Gravity-Driven Drop Test. A specimen of EPS crushable foam having a square base with the side length of $250 \mathrm{~mm}$ and the height of $400 \mathrm{~mm}$ was secured to the ground. A $650 \mathrm{~mm}$ long cylinder $(3.39 \mathrm{~kg})$ with a diameter of $50 \mathrm{~mm}$ and a semi-spherical head was dropped on the specimen through a cylinder tube guide. The altitude of the long rod drop was 6 meters and the projectile accelerated due to gravity and reached the velocity of $10.85 \mathrm{~m} / \mathrm{s}$ before hitting the specimen. The set up of the experiment is shown in Figure 4. A localized damage was observed on the projected area of the projectile and the surrounding surface area of the specimen was not

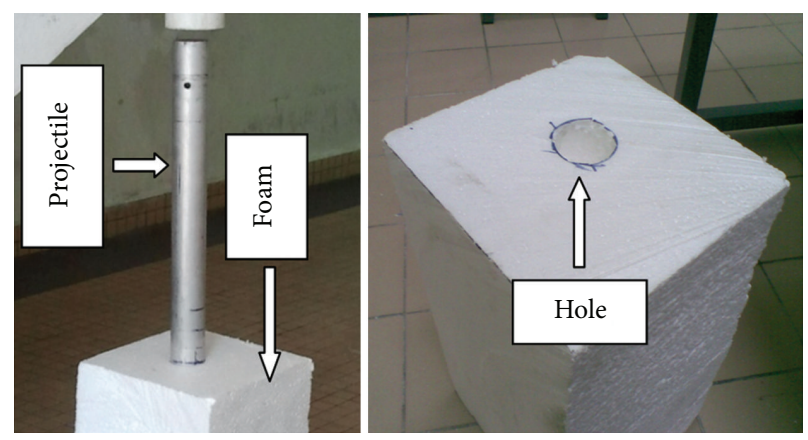

FIGURE 5: Localized damage on the specimen.

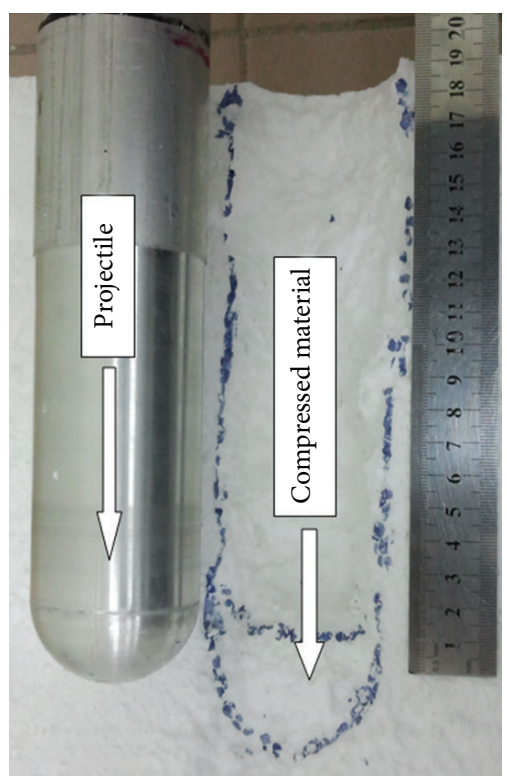

FIGURE 6: Depth of penetration of projectile into EPS foam specimen.

affected as seen in Figure 5. This damage was confined to a straight cylindrical hole in the foam specimen. Due to the small elastic recovery of the specimen, the projectile bounced up slightly after reaching the maximum depth of penetration. The damage in the specimen was highlighted as shown in Figure 6. Table 2 summarizes the results of the drop test experiment.

\section{Numerical Simulation}

3.1. Compression Test Simulation. The simulation of the quasi static compression test was successfully performed using LSDyna. LS-Dyna provides many material models for different types of foams [16]. However, based on previous work by Ozturk and Anlas [12], the best candidate for modeling EPS crushable foam is MAT_CRUSHABLE_FOAM. This material model required the input of five parameters: density of material, modulus of elasticity, Poisson's ratio, stress strain curve, tensile stress cutoff, and damping coefficient. The first four parameters were found experimentally. However, tensile cutoff and viscous damping coefficient were obtained 
TABLE 2: Maximum depth of penetration of the projectile.

\begin{tabular}{lc}
\hline & DOP $(\mathrm{mm})$ \\
\hline Specimen 1 & 189 \\
Specimen 2 & 190 \\
Specimen 3 & 186 \\
Specimen 4 & 187 \\
\hline Average & 188 \\
\hline
\end{tabular}

from the literature [12]. The parameters for the material model are listed in Table 3. The model was finely meshed to obtain accurate results. The lower nodes of the model were fixed while the upper nodes were given a prescribed motion at $500 \mathrm{~mm} / \mathrm{min}$. The results of the simulation are listed in Figure 7. A comparison between the simulation and the experimental results show very small difference and thus verifies the material model developed for compression.

3.2. Drop Test Simulation. The material model developed for the compression test simulation must be improved before it could be used in the drop test simulation. The main reason is that in the long rod impact the compression force is localized in a small area on the surface of the foam thus creating a combination of compression and shear. The material failure was simulated with the aid of MAT_ADD_EROSION based on the plastic strain and tensile stress [4]. Without introducing failure in the material model, the crushable foam deformation due to the localized force shows problematic furrowing [4] and an unrealistic dent shape as shown in Figure 8. The brittle failure mode cannot be obtained without using an appropriate failure criterion.

The existing model was improved to avoid the negative volume error which occurs due the large deformation in the foam. To prevent this error, the stress strain curve was extended exponentially at large strains [17]. The extended curve is shown in Figure 9. Also, one point integration solid element was used with hourglass control type 2 [18]. To avoid mesh tangling in high compression areas, interior contact was utilized with the activation thickness factor of 0.1. Contact interior type 2 was activated to control a combined mode of compression and shear in LS-DYNA [4].

Allowing the foam elements to fail and erode causes another problem. Some elements on the surface of foam will erode and the projectile will come into contact with some of the elements within the foam. Thus, surface to surface contacts are not recommended. To overcome this problem, AUTOMATICE_NODE_TO_SURFACE contact was used and a set of all the foam nodes was defined that were used in the contact command. However, this method carries a computational penalty.

By default, LS-DYNA removes the mass of the eroded elements to increase the stability of the calculation. However, the mass of the eroded elements must be considered as the reduction of mass might cause incorrect results. In CONTROL_CONTACT card, the value of ENMASS is changed to unity so that the mass of the eroding nodes is retained and continue to be active in contact [19].

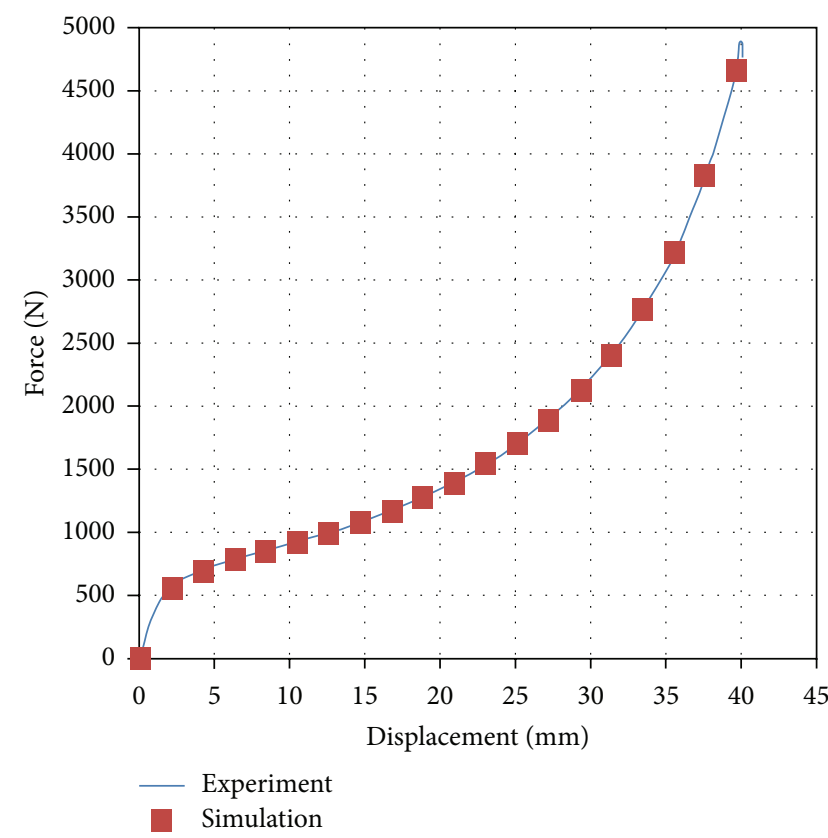

FIGURE 7: Comparison between the experimental and simulation results of the static compression test at $500 \mathrm{~mm} / \mathrm{min}$.

\section{Discussion}

4.1. Quasi Static Compression Test. The compression test was conducted to obtain the material properties of EPS crushable foams as well as to develop a preliminary material model. The most important required properties for modeling the material are the density, stress strain curve, the elastic modulus, and Poisson's ratio. These properties were found experimentally. The elastic modulus and stress strain curve were found to be dependent on the strain rate. As the strain rate increases, the elastic modulus increases and the stress strain curve becomes stiffer. As for Poisson's ratio, it was found to be independent of the strain rate and was always equivalent to zero [12].

A Comparison between the experimental and simulation results shows the capability of the model to reproduce the stress strain curve with acceptable accuracy as shown in Figure 7. Therefore, the suggested material parameters are capable of accurately predicting the load and deformation of EPS crushable foams.

However, it should be noted that even though the material model showed good accuracy in the compression test simulation, it is still a preliminary model and needs to be improved if it were to be used for large deformation and failure simulations of EPS foam.

Failure due to shear or tension must be introduced in the material model. Although crushable foams are not used under tension or shear loading, localized impact or the geometry of the crushable foam might result in a combined mode of shear, tension and compression [2].

4.2. Drop Test. The drop test experiment serves as an additional verification of the suggested material parameters. The 
TABLE 3: Input card for MAT_CRUSHABLE_FOAM.

\begin{tabular}{lccc}
\hline Parameter & Description & Value & \\
\hline MID & Material ID number & 12.5 & Units \\
RO & Density & 0.0022 & $\mathrm{Kg} / \mathrm{m}^{3}$ \\
E & Young's Modulus & 0 & $\mathrm{GPa}$ \\
PR & Poisson's ratio & $0.1 \times(10)^{-3}$ \\
LCID & Load curve ID for nominal stress versus strain & 0.5 \\
TSC & Tensile stress cut-off & $\mathrm{GPa}$ \\
DAMP & Rate sensitivity via damping coefficient & \\
\hline
\end{tabular}

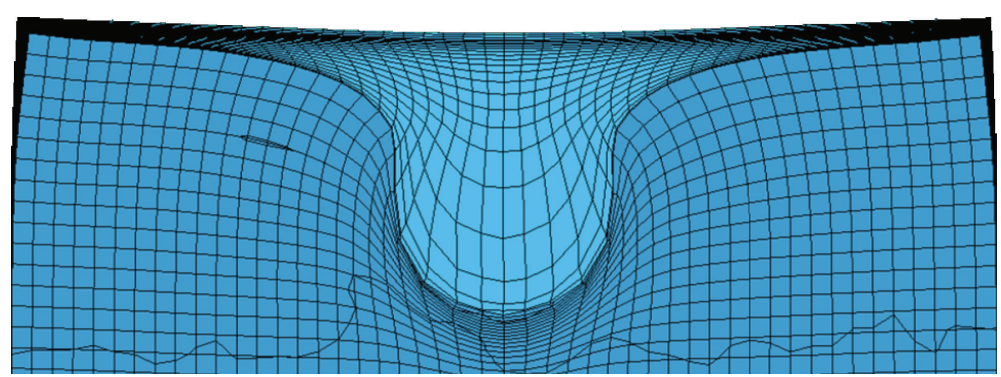

FIGURE 8: Deformation of EPS foam without introducing failure criterion.

first problem encountered in the simulation was the negative volume problem due to instability. The existing model can withstand compression until only around 80 percent of its original length. This is because the stress strain curve used in the model was obtained from the compression test in which the compression limit was 80 percent. However, in the drop test experiment, due to the high kinetic energy of the projectile, the crushable foam elements might be compressed more than 80 percent of their original length. It may occur that the strain in the simulation exceeds the last point of the stress-strain curve. If this happens, LS-DYNA extends the curve linearly with last slope of the curve. This might lead to relatively small stress values and the negative volume problem might occur.

The negative volume error problem was prevented by adopting two approaches. First, the stress strain curve was exponentially extended at large strains as shown if Figure 9. This can be a very effective approach. Another important parameter which greatly helps in preventing the negative volume error is by introducing the "contact interior" in LSDYNA. This type of contact was especially designed to be used for simulating soft materials. The contact interior type 2 was activated, which was designed to control combined modes of compression and shear.

In the experiment, the brittle failure was observed in the material due to shear loads. To simulate this mode of failure, ADD_EROSION was utilized which allows the introduction of failure criteria in the material model as MAT_CRUSHABLE_FOAM does not allow material erosion. The failure criteria defined was the maximum tensile stress and maximum plastic strain. The values of these criteria were found by visual investigation and comparison between experiment and the simulation. The points at which the material starts to crack and fail in the experiment were identified, and the respective failure criteria values were introduced into simulation by trial and error method.

Comparing the projectile depth of penetration in the experiment and simulation validates the developed material parameters. As shown in Figure 10, the depth of penetration profile obtained in the simulation shows that the projectile reaches the maximum depth of penetration of $188 \mathrm{~mm}$ at 34 milliseconds. This value of the maximum depth of penetration matches the experimental average value as shown in Table 2. Also, the graph shows that the depth of penetration slightly decreases after reaching the maximum depth of penetration then increases back to the maximum. This is interpreted as the long rod projectile bouncing back slightly after reaching the maximum depth of penetration, which was actually observed in the experiment. Furthermore, visual comparison between the physical testing and numerical simulations shows the similarity in the failure mode of the crushable foams. As depicted in Figure 11, the damage on the foam was localized on the projected area of projectile and the failure occurs due the shear strain.

\section{Conclusions}

Compression tests on EPS crushable foams were carried out at different strain rates. The effect of strain rate on the material properties was established. It was found that at higher strain rates the material is able to withstand higher loads and absorbs more energy. Moreover, elastic modulus and yield strength increments were found to be proportional to the strain rate increase.

Compression test simulations were successfully performed and the results were validated by the experimental work. The material model was capable to reproduce the stress strain curve with acceptable accuracy. 

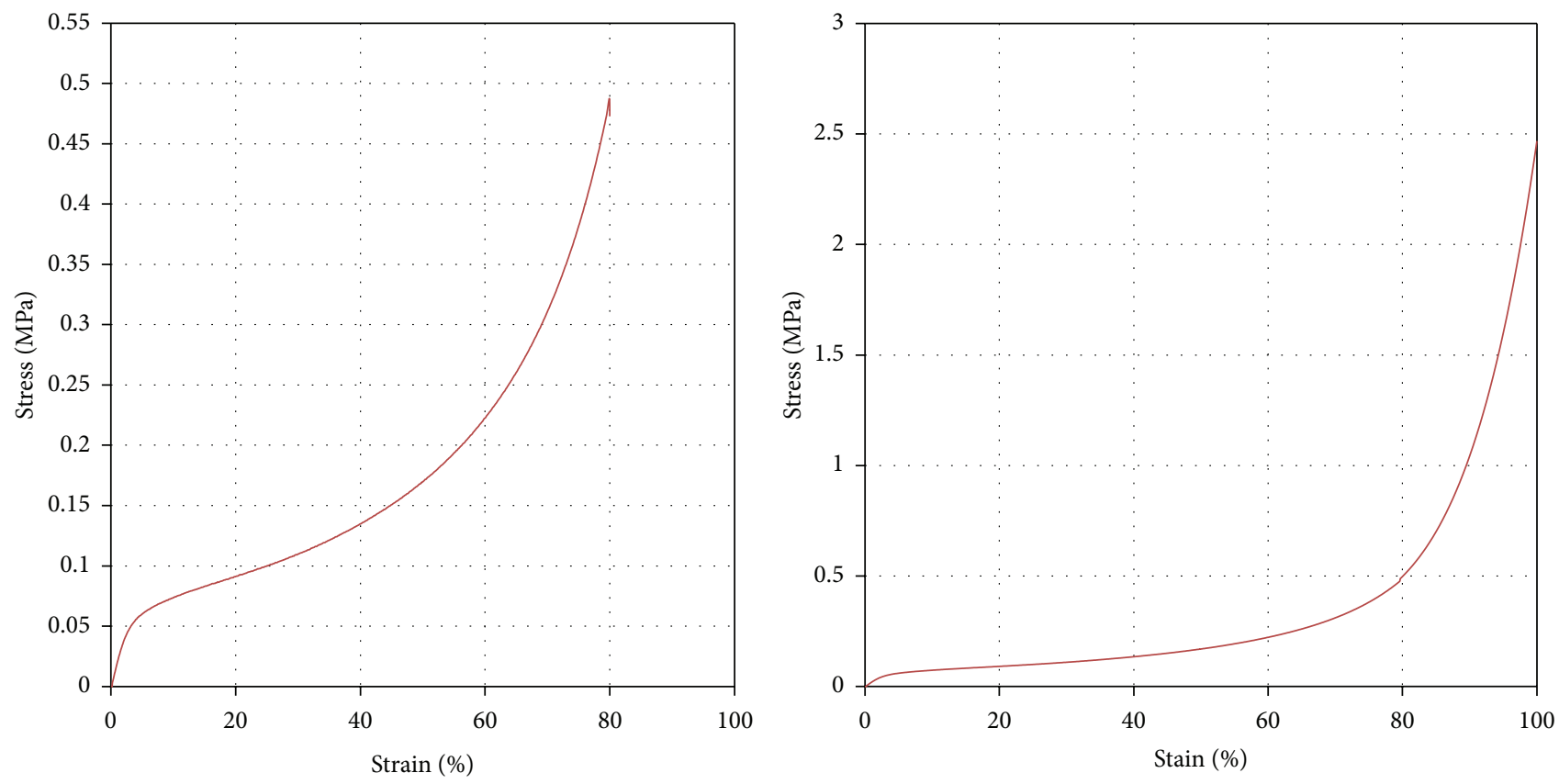

Figure 9: Original (left) and extended (right) stress-strain curve.

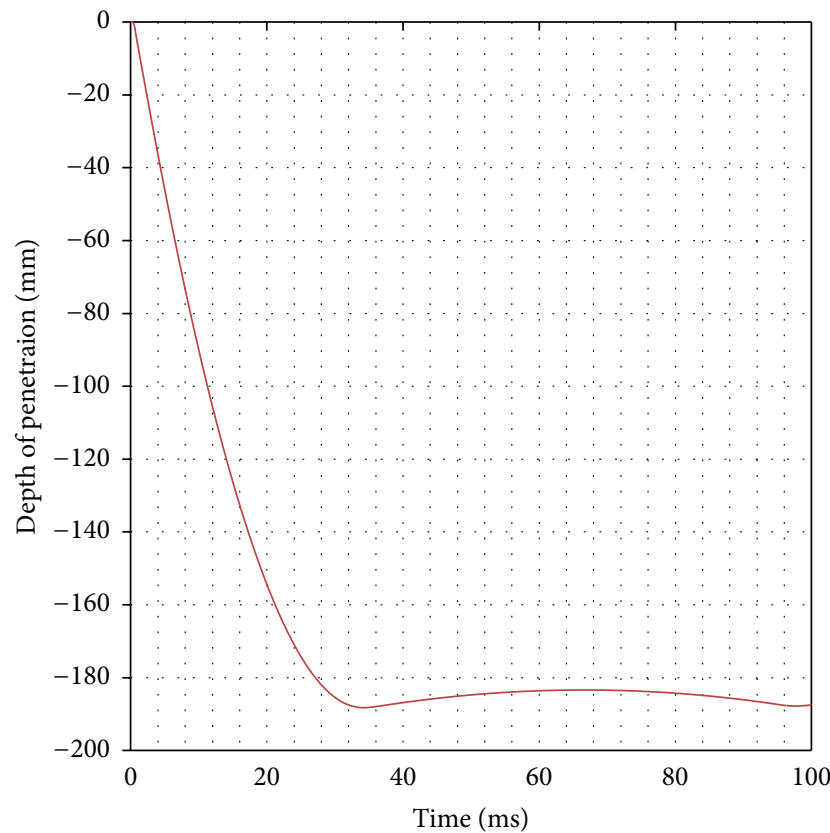

Figure 10: Missile depth of penetration (simulation results).

Drop tests using long rod projectile impact against EPS crushable foam were conducted. The depth of penetration was recorded and the average value was calculated. The failure mode and the deformation in the specimen were investigated. Numerical simulations were performed using the enhanced material parameters along with an appropriate failure criterion that were able to reproduce the failure modes observed during the experiments. Maximum depth of

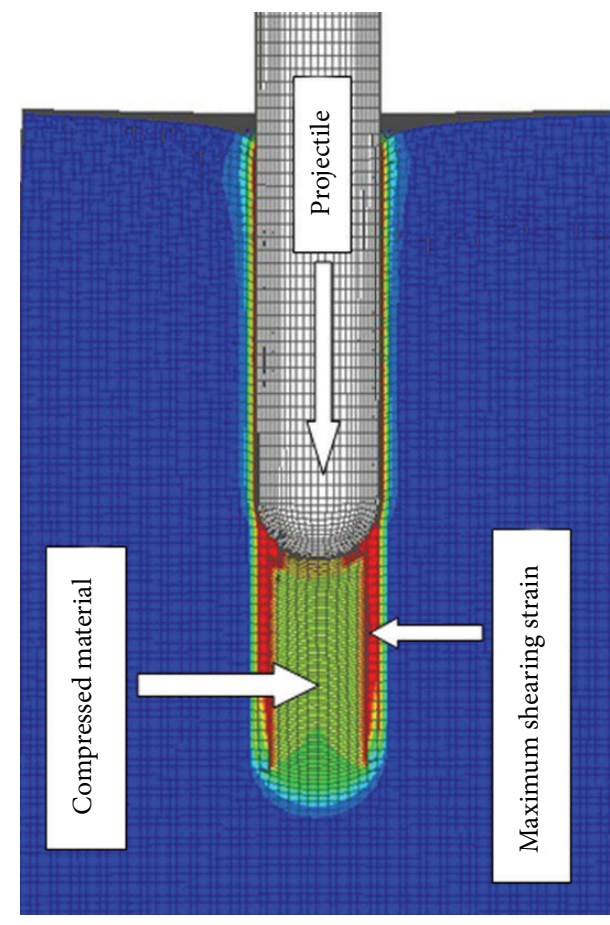

FIGURE 11: Foam failure process in numerical analysis.

penetration obtained in LS-DYNA simulations agreed closely with experimental work.

\section{Conflict of Interests}

The authors declare that there is no conflict of interests regarding the publication of this paper. 


\section{References}

[1] C. Gontier, A. Bouchou, and C. Vinot, "A mechanical model for the computation of phenolic foams in compression," International Journal of Mechanical Sciences, vol. 43, no. 10, pp. 23712384, 2001.

[2] B. Croop and H. Lobo, "Selecting material models for the simulation of foams in LS-DYNA," in Proceedings of the 7th European LS-DYNA Conference, pp. 1-6, 2009.

[3] A. Droste and J. Rögger, "Crash performance increase with structural BETAFOAMTM," in Proceedings of the LS-DYNA Anwenderforum, pp. 37-44, Frankenthal, Germany, 2007.

[4] M. S. Matthew Barsotti, "Comparison of FEM and SPH for modeling a crushable foam aircraft arrestor bed," in Proceedings of the 11th International LS-DYNA Users Conference, vol. 16, pp. 37-54, 2010.

[5] R. W. Bielenberg and J. D. Reid, "Modeling crushable foam for the SAFER racetrack barrier," in Proceedings of the 8th International LS-DYNA Users Conference, vol. 6, pp. 1-10, 2004.

[6] W. Robert Bielenberg and D. John Reid, "Modeling rebound of foam backed race track barriers," in Proceedings of the 8th International LS-DYNA Users Conference, vol. 6, pp. 42-50, 2008.

[7] G. Downie, "Crushable foam wrap mitigates subsea casing failures," 2009, http://www.epmag.com/Production/Crushablefoam-wrap-mitigates-subsea-casing-failures_33864.

[8] Q. Liu, G. Subhash, and X.-L. Gao, "A parametric study on crushability of open-cell structural polymeric foams," Journal of Porous Materials, vol. 12, no. 3, pp. 233-248, 2005.

[9] L. Aktay, A. K. Toksoy, and M. Güden, "Quasi-static axial crushing of extruded polystyrene foam-filled thin-walled aluminum tubes: experimental and numerical analysis," Materials and Design, vol. 27, no. 7, pp. 556-565, 2006.

[10] Z. H. Tu, V. P. W. Shim, and C. T. Lim, "Plastic deformation modes in rigid polyurethane foam under static loading," International Journal of Solids and Structures, vol. 38, no. 50-51, pp. 9267-9279, 2001.

[11] M. Wronski, "A new hypoelastic model of the mechanical behaviour of polyurethane foams," Computational Materials Science, vol. 5, no. 1-3, pp. 271-276, 1996.

[12] U. E. Ozturk and G. Anlas, "Finite element analysis of expanded polystyrene foam under multiple compressive loading and unloading," Materials and Design, vol. 32, no. 2, pp. 773-780, 2011.

[13] G. Slik, G. Vogel, and V. Chawda, "Material model validation of a high efficient energy absorbing foam," in Proceedings of the 5th LS-DYNA Forum, Materials Engineering Centre, Ulm, Germany, 2006.

[14] V. I. Rizov, "Low velocity localized impact study of cellular foams," Materials and Design, vol. 28, no. 10, pp. 2632-2640, 2007.

[15] P. A. Du Bois, S. Kolling, M. Koesters, and T. Frank, "Material behaviour of polymers under impact loading," International Journal of Impact Engineering, vol. 32, no. 5, pp. 725-740, 2006.

[16] LS-DYNA Theory Manual Version, vol. 970, Livermore Software Technology.

[17] S. Bala, "Best practices for modeling recoverable low density foams-by example," 2006, http://blog2.d3view.com/bestpractices-for-modeling-recoverable-low-density-foams-by-example/.
[18] K. Weimar and J. Day, "Negative volumes in brick elements," 2003, http://www.dynasupport.com/howtos/element/negativvolumes-in-brick-elements.

[19] Q. H. Shah and H. Abid, "LS-PrePost \& LS-DYNA tips," in LSDYNA for Beginners: an Insight Into Ls-Prepost and Ls-Dyna, $\mathrm{p}$. 116, Lambert, Saarbrücken, Germany, 2012. 

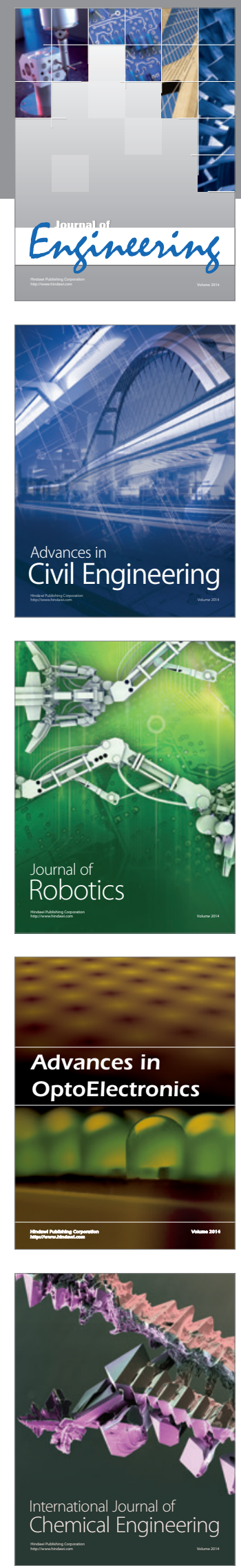

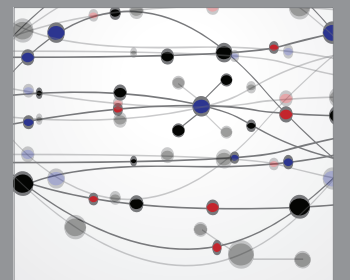

The Scientific World Journal
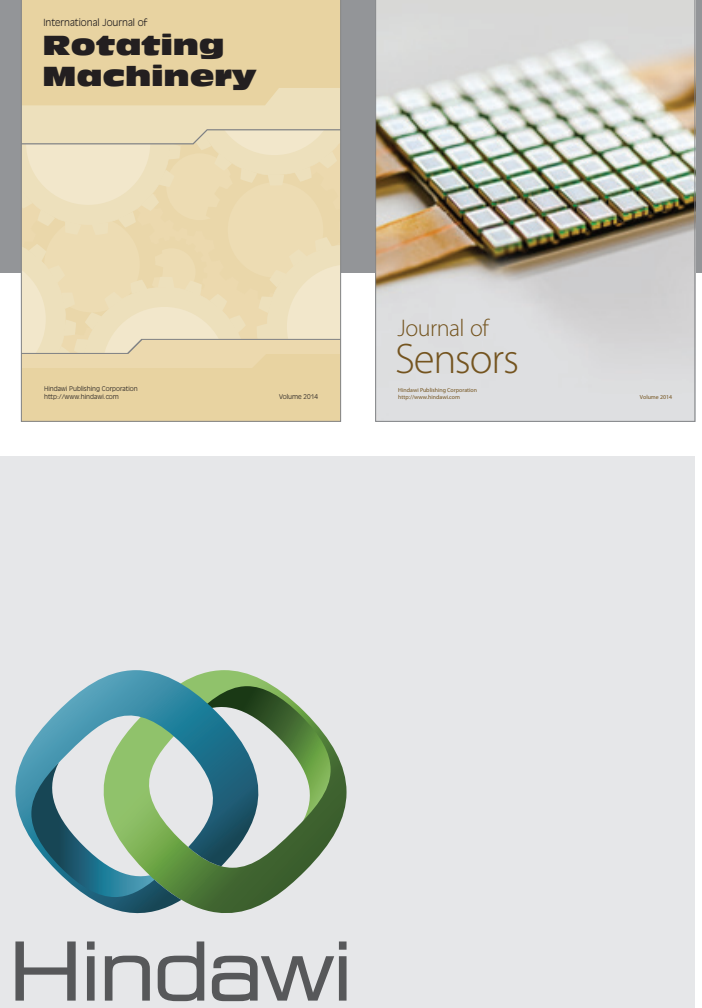

Submit your manuscripts at http://www.hindawi.com
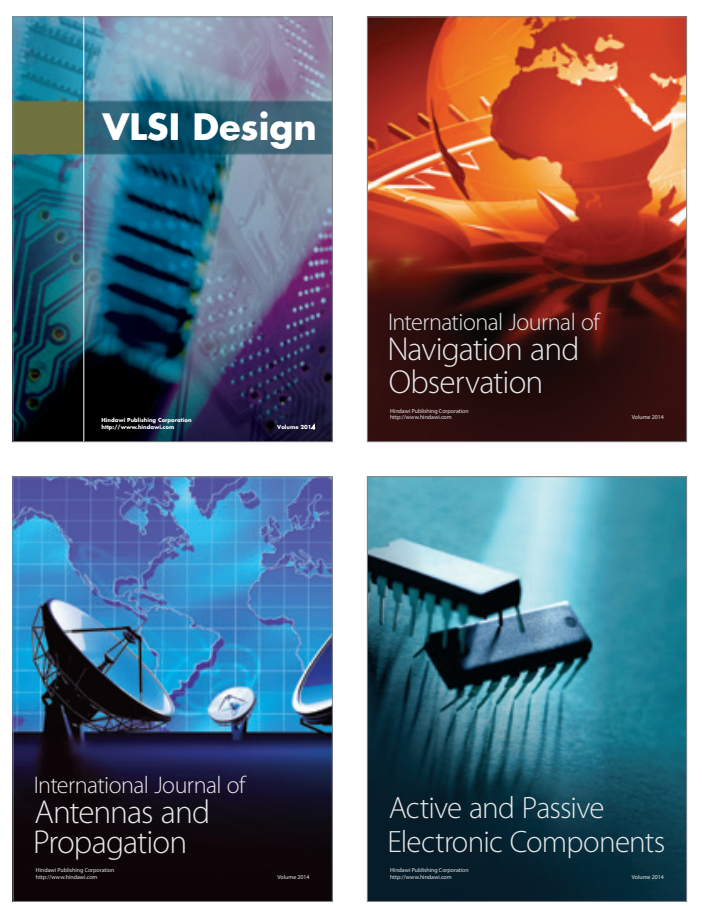
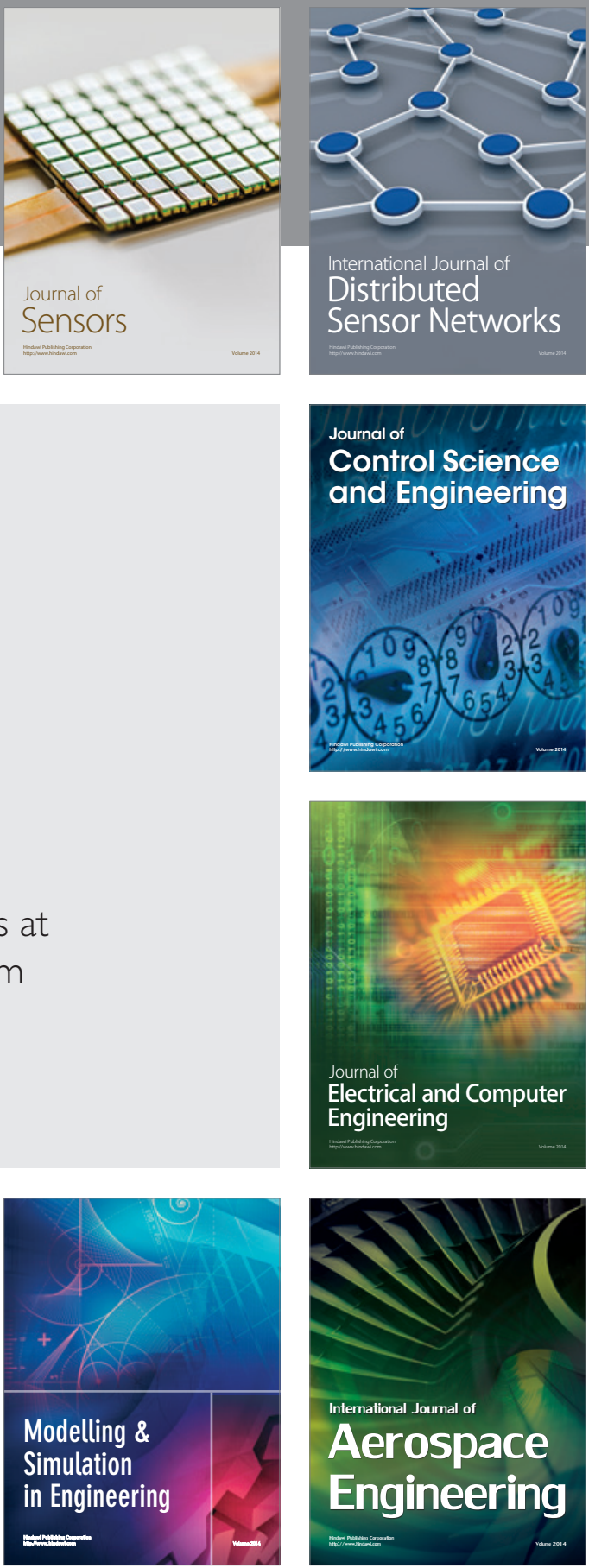

Journal of

Control Science

and Engineering
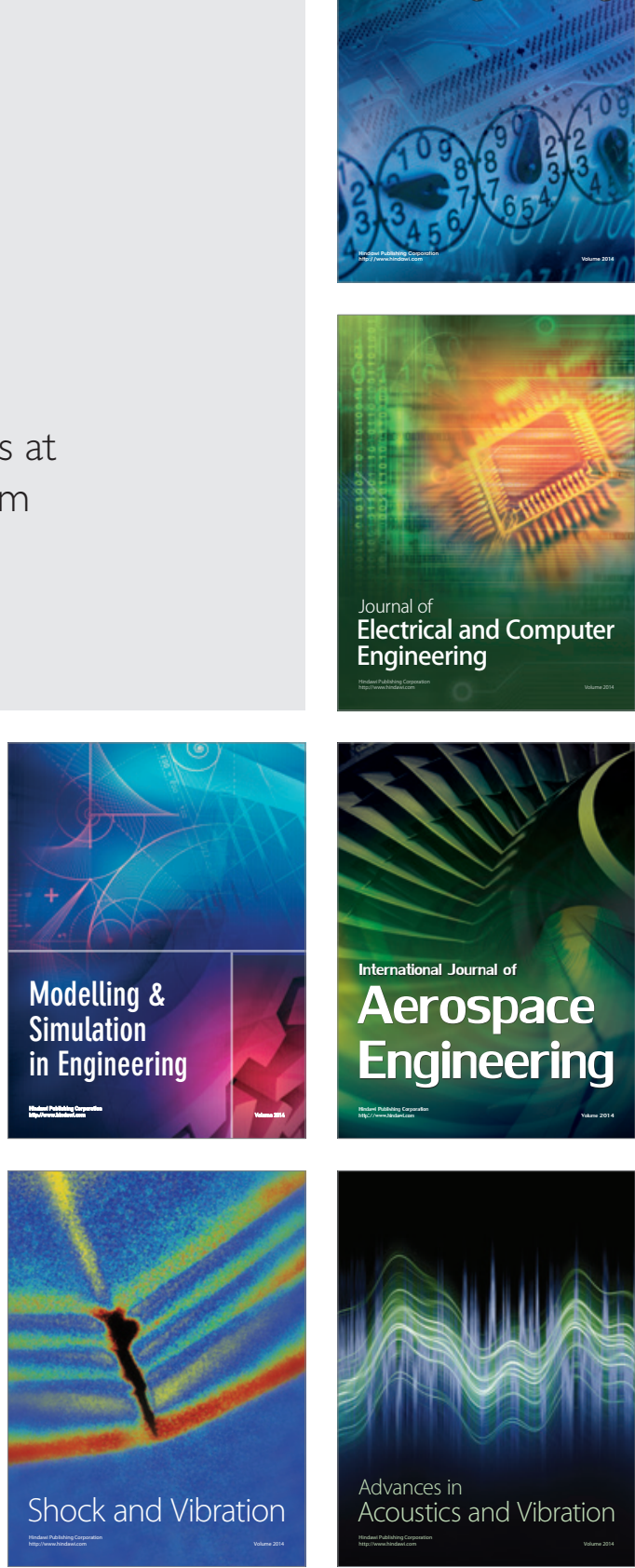